\title{
Detection of Surra (trypanosomiasis) positivity in humans in an outbreak area of Indonesia
}

\author{
Dyah Haryuningtyas Sawitri, ${ }^{1}$ April Hari Wardhana, ${ }^{1}$ Mohamad Sadikin, ${ }^{2}$ Heri Wibowo ${ }^{3}$
}

\section{pISSN: 0853-1773 • elSSN: 2252-8083 https://doi.org/10.13181/mji.v28i2.1767 Med J Indones. 2019;28:196-202}

Received: January 11, 2017

Accepted: March 31, 2019

\section{Authors' affiliations:}

${ }^{1}$ Indonesian Research Centre for Veterinary Sciences, Bogor, Indonesia, ${ }^{2}$ Department of Biochemistry and Molecular Biology, Faculty of Medicine, Universitas Indonesia, Jakarta, Indonesia, ${ }^{3}$ Department of Parasitology, Faculty of Medicine, Universitas Indonesia, Jakarta, Indone

\section{Corresponding author:}

Dyah Haryuningtyas Sawitri Indonesian Research Centre for Veterinary Sciences, Balai Besar Penelitian Veteriner. Jalan RE. Martadinata No. 30, Bogor 16114 , Indonesia

Tel/Fax: +62-251-8331048

E-mail: dyah.haryuningtyas@gmail.com

\begin{abstract}
BACKGROUND Surra is an infection caused by a blood protozoan parasite, Trypanosoma evansi, and transmitted by blood-sucking insects. The parasite generally infects only animals; however, it was reported to infect an Indian cattle farmer in 2004, followed by reports of other human cases. The most severe Surra outbreak in Indonesia occurred in Sumba Island during 2010-2012, resulting in the death of more than 2,000 livestock. This study was conducted to explore the serological status of farmers who have intensive contact with their livestock against T. evansi infection in Southwest Sumba district.
\end{abstract}

METHODS A total of 24 serum samples were collected from farmers living in the Surra outbreak area. All sera were tested using both card agglutination test for trypanosomiasis/T. evansi (CATT/T. evansi) and field enzyme-linked immunosorbent assay (FELISA).

RESULTS Of the 24 serum samples, 4 (16.7\%) samples were seropositive for the antigen T. evansi using both tests. This is the first report of human trypanosomiasis (Surra) in Indonesia. Unfortunately, the clinical manifestations of farmers with positive Surra infection were not reported because all sera samples used in this study were obtained from the Public Health Service with no reports of clinical signs from the respondents.

CONCLUSIONS Farmers living in the Surra outbreak area have a high risk of being infected with T. evansi due to their potential frequent contact with Surra vectors. Therefore, T. evansi infection in humans requires attention as it might have the potential to develop as a new emerging zoonotic disease in Indonesia.

KEYWORDS Trypanosoma evansi, human serum, CATT/T. evansi, FELISA
Trypanosomes are blood protozoa that infect humans, livestock, and wild animals throughout the world and are most often transmitted by bloodsucking insects. ${ }^{1}$ Human trypanosomiasis is endemic in Africa and South America. ${ }^{2}$ African trypanosomiasis in humans is caused by Trypanosoma brucei gambiense (chronic form) or T. b. rhodesiense (acute form), which is the cause of sleeping sickness or humananimal trypanosomiasis, whereas South American trypanosomiasis (Chagas diseases) is caused by T. cruzi. Sleeping sickness and Chagas diseases are transmitted by Tsetse flies and reduviid bugs/Triatominae, respectively. ${ }^{2}$ In addition to these human trypanosomes, there are various other species that cause animal trypanosomiasis with a wide geographic distribution. $T$. evansi is a pathogenic trypanosome that causes Surra in livestock in Asia, Africa, South America, and parts of Europe and is transmitted by hematophagous flies (Tabanids and Stomoxys calcitrans). ${ }^{3}$ Another species, T. vivax, causes nagana disease in animals in Africa and is transmitted by Glossina morsitans. Furthermore, T. congolense and T. brucei brucei have been reported to cause trypanosomiasis in animals in Africa. In addition, T. equiperdum was reported to infect horses 
in Europe, America, North Africa, and India. ${ }^{3}$ Another non-pathogenic parasite, T. lewisi, has been reported to infect rodents and transmitted by fleas. ${ }^{4}$

Human infection by animal species of Trypanosoma is considered to be impossible because of the presence of a trypanolytic factor in human serum. Nevertheless, the first case of human infection with T. evansi was reported in the central part of India (Seoni village, Taluka Sindevahi, district of Chandrapur, Maharashtra State) in 2004.5 The disease was found in a cattle farmer who had intensive contact with his livestock. It was reported that the disease could have occurred as the farmer was deficient in apolipoprotein L1 (APOL1), ${ }^{6}$ a component of human serum with trypanocidal activity. ${ }^{7}$ In addition, three other cases have been reported worldwide (Table 1 ).

Human innate immunity against $T$. evansi is induced by the trypanolytic activity of a human-specific apolipoprotein bound to high-density lipoproteins, termed as APOL1. ${ }^{6}$ APOL1 is taken up by the parasite via endocytosis and triggers the formation of anionselective pores in the lysosomal membrane, which induces uncontrolled osmotic swelling of this compartment and subsequent cell death. ${ }^{11}$ The lack of nonspecific immune protection of APOL1 in humans or the development of new capacity in the parasite to respond to nonspecific immunity may also lead to the evolution of most of the trypanosome pathogens. ${ }^{12}$ Similarly, the results of another study reported by Lai et $\mathrm{al}^{13}$ demonstrated tolerance toward T. evansi stock in response to normal human serum (NHS). This report was supported by Van Vinh Chau et $\mathrm{al}^{10}$ who described the first human case of T. evansi infection in Asia without any APOL1 deficiency (healthy individual).

The number of atypical human infections caused by $T$. evansi has been increasing, due to which some scientists have created a new network on atypical human infection by animal trypanosomes (NAHIAT).
This network is intended to coordinate information and research activities regarding atypical human trypanosomiasis. ${ }^{4}$ Indonesia is an endemic country for Surra that infects livestock, and there have been few outbreaks in 2010-2016. However, there is a lack of a study on atypical human trypanosomiasis in Indonesia. Therefore, the primary aim of the present study was to assess the details regarding the disease, particularly when there were Surra outbreaks. One of the methods used for diagnosing Surra is the serological test. Various serological tests such as indirect immunofluorescent antibody test, enzymelinked immunosorbent assay (ELISA), and card agglutination test for trypanosomiasis (CATT) are used to identify specific antibody responses. CATT/T. evansi is highly specific in detecting circulating antibodies as it targets the variant surface glycoprotein RoTat 1.2. The CATT/T. evansi technique for detecting antibody was originally described by Bajyana Songa and Hamers and converted into a test kit by the Institute of Tropical Medicine, Belgium. ${ }^{14}$ This kit has a high measure of validity, and it is economical and applicable in largescale screening. Furthermore, CATT/T. evansi is a rapid and easy test that can be performed under both laboratory and field conditions. ${ }^{15}$ High test accuracy has been reported for CATT/T. evansi in livestock raised in various regions such as Punjab, India, ${ }^{16}$ Mesir, ${ }^{17}$ Indonesia, ${ }^{18}$ and Kenya. ${ }^{19}$

Field ELISA (FELISA) is an immunostick assay technique based on ELISA and developed as an alternative serological method with high accuracy. This diagnostic kit was constructed by the Indonesian Research Center for Veterinary Science, Bogor, and designed for rapid and practical application in the field to detect antibodies in the serum of infected animals. ${ }^{20}$

Sumba Island was the only region to be free of T. evansi infection until 2009. However, the Surra outbreak that occurred in 2010-2012 resulted in the

Table 1. Trypanosomiasis caused by T. evansi (Surra) in humans

\begin{tabular}{lccccccc}
\hline Country & $\begin{array}{c}\text { Occupation (number } \\
\text { of farmers) }\end{array}$ & Year & $\begin{array}{c}\text { Parasite } \\
\text { identification } \\
\text { methods }\end{array}$ & $\begin{array}{c}\text { Clinical } \\
\text { symptom }\end{array}$ & Treatment & Result & Reference \\
\hline India, Seoni & Farmer (1) & 2004 & $\begin{array}{c}\text { Morphology } \\
\text { serology, PCR }\end{array}$ & Fever & Suramin & Recovered & 5 \\
India, Kolkata & Farmer (1) & 2005 & Morphology & Fever & - & Death & 8 \\
Mesir & Farmer (1) & 2010 & Morphology & Fever & - & Recovered & 9 \\
Vietnam & Factory worker (1) & 2015 & $\begin{array}{c}\text { Morphology } \\
\text { serology, PCR }\end{array}$ & Fever & Suramin & Recovered & 10 \\
\hline
\end{tabular}


Table 2. Sera samples of farmers in Southwest Sumba district used in the present study

\begin{tabular}{lccccc}
\hline \multirow{2}{*}{ Status area } & \multirow{2}{*}{$\begin{array}{c}\text { Name of community health } \\
\text { center (Puskesmas) }\end{array}$} & Location (Subdistrict) & \multicolumn{2}{c}{ Sex, $\mathrm{n}$} & Range of age (years old) \\
\cline { 4 - 5 } Outbreak & Watu Kuwala & West Wewena & 6 & Female & $18-60$ \\
Outbreak & Wallandimu & Kodi Bangedo & 6 & 1 & $25-47$ \\
Outbreak & Rada Mata & Loura & 6 & 0 & $32-35$ \\
Outbreak & Waimangura & West Wewena & 4 & 1 & $19-46$ \\
Non-endemic & - & Jakarta (City) & 0 & 8 & $17-20$ \\
Total & & & 22 & 10 & \\
\hline
\end{tabular}

death of more than 2,000 livestock (buffaloes, cattle, and mostly horses) due to T. evansi infection. ${ }^{21}$ It was reported to be the most severe Surra outbreak in Indonesia, and the parasite was believed to be introduced from Sumbawa Island (Surra endemic area) when there was traditional horse racing. Considering Surra cases in humans and to support the NAHIAT agenda, this study was performed to conduct serological tests using both CATT/T. evansi and FELISA kits on farmers who have intensive contact with their livestock in some Sumba outbreak regions.

\section{METHODS}

\section{Serum samples}

This study was approved by the Ethics Committee of the Faculty of Medicine, Universitas Indonesia, number $809 /$ UN2.F1/ETHICS/2015. A total of 24 sera samples (22 males and 2 females) were collected from farmers living in three subdistricts (West Wewewa, Kodi Bangedo, and Loura) of Southwest Sumba district in 2012 during an outbreak of Surra. Furthermore, 8 serum samples were obtained from Jakarta (Surra non-endemic areas) that served as seronegative controls (Table 2). Jakarta was selected for collecting seronegative samples because there has been no report of Surra cases in Jakarta infecting either livestock or humans. The seronegative control samples were selected on the basis of few parameters, i.e., the individuals were healthy, they never had contact with livestock, they lived in areas with no farms (town), and there were no vectors of Surra found in the area where they lived. Based on these parameters, all the available samples were found to be collected from female individuals. There was no difference in response to the serological test for Surra infection between males and females. All sera were maintained at $-20^{\circ} \mathrm{C}$ for further analysis.

\section{FELISA}

Each sample was diluted in phosphate-buffered saline (PBS, pH 7.2) containing 0.05\% Tween 20 (1:10) and shaken homogeneously. Subsequently, $800 \mu$ liluted serum sample was poured into an immunostick tube, incubated at room temperature for $10 \mathrm{~min}$, and then removed and washed with tap water. Each immunostick was introduced and immersed in tubes containing conjugated (1:6000) anti-human Ig G-HRP (Sigma Chem, USA), incubated at room temperature for $10 \mathrm{~min}$, and then washed with tap water. Finally, the immunostick was submerged in a tube containing the substrate ODN (o-Dianisidine; Sigma Chem, USA) for $3 \mathrm{~min}$ and then washed with tap water. A positive response was marked by a color change on the immunostick surface coated with antigen. ${ }^{20}$

\section{CATT/T. evansi}

Approximately $45 \mu \mathrm{l}$ of the antigen was poured into the circular reaction zones of the supplied plastic card and mixed with $25 \mu$ of the test sera according to the manufacturer's instructions. The dropper was held vertically, and drops were allowed to fall freely without touching the card to maintain a constant volume. The antigen and serum mixture was mixed and spread properly using a clean plastic stirring rod to approximately $1 \mathrm{~mm}$ from the rim of the test area; the stirring rod was wiped with a sterile filter paper after each use. Each plastic card contained two reaction zones for the positive and negative controls. The card was agitated for $5 \mathrm{~min}$ at $70 \mathrm{~g}$ after positioning on a flat bed of an electric orbital rotator. After 5 min, the results were read before removing the card from the rotator. A reaction was considered to be positive when the agglutination was visible to the naked eye. ${ }^{22}$ Human sera that were positive for anti-trypanosome antibodies by CATT demonstrated different degrees 
of agglutination graded as +++ (very highly positive), ++ (highly positive), + (moderately positive), \pm (mildly positive), and - (negative).

\section{RESULTS}

All samples from Southwest Sumba district were collected from farmers who had intensive contact with livestock to identify whether they had an opportunity to have contact with any vectors of Surra, such as the tabanid fly, the stable fly (S. calcitrans), or other hematophagous flies. When the vectors bite the farmers, they might show a positive antibody to $T$. evansi in their serum sample. Conversely, all samples from Jakarta were collected from those people who never had any contact with livestock and vectors, and hence they were used as the seronegative control group. Unfortunately, there were no reports of any clinical manifestations of farmers who were positive for Surra because all serum samples used in this study were obtained from the Public Health Service without the details of any clinical signs from the respondents. Based on the results of both FELISA and CATT/T. evansi, 4 of 24 farmer serum samples (16.67\%) collected from Southwest Sumba district were confirmed to be seropositive (moderately positive), whereas all human serum samples collected from the non-endemic area (Jakarta) showed a seronegative response (Table 3). A positive CATT/T. evansi response was shown by the sand formation in sample numbers 1 and 5 (Figure 1), indicating that there was agglutination between the antigen CATT/T. evansi and anti-T. evansi antibodies from the farmers' sera. Meanwhile, a positive FELISA response was shown by the color change from white to an orange dot on the immunostick. Nevertheless, these experiments were not followed by examination of blood samples to confirm the presence of parasites in

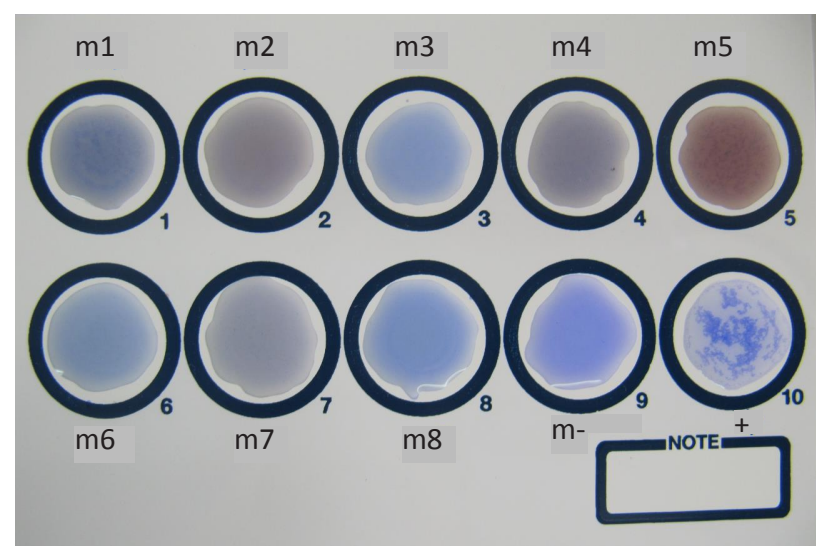

Figure 1. Result of CATT/T. evansi test against farmers' serum from Surra outbreaks areas characterized by the presence of agglutination between antigens and antibodies (looks like sand). Circle zone no. 9 is a negative control sample, and no. 10 is a positive control sample. Sample no. 1 and 5 are positive farmer sera. CATT= card agglutination test for trypanosomiasis

the farmers' peripheral blood samples based on either microhematocrit centrifuge technique or polymerase chain reaction (PCR). Furthermore, no clinical symptoms were reported from all respondents who showed either seropositive or seronegative responses to T. evansi.

\section{DISCUSSION}

This study was conducted to assess whether farmers were exposed to T. evansi infection during the outbreak in 2010-2012. The results demonstrated that a few farmers (16.7\%) living in Southwest Sumba district were serologically positive for Surra tests. Another Surra surveillance study was also conducted by Wardhana et $\mathrm{al}^{23}$ who collected serum samples from livestock from the same area in the same year (Southwest Sumba). They reported that 38\% (57/150) of livestock were seropositive on the basis of CATT/T.

Table 3. Results of serological tests of farmers' sera based on CATT/T. evansi and FELISA analyses

\begin{tabular}{|c|c|c|c|c|c|c|}
\hline \multirow{2}{*}{ Location (village, subdistrict) } & \multicolumn{2}{|c|}{ CATT T. evansi } & \multicolumn{2}{|c|}{ FELISA } & \multirow{2}{*}{ Sex } & \multirow{2}{*}{ Age (years old) } \\
\hline & + & - & + & - & & \\
\hline Watu Kawula, West Wewewa & 1 & 5 & 1 & 5 & Male & 18 \\
\hline Walla-Ndimu, Kodi Bangedo & - & 7 & - & 7 & - & - \\
\hline Lete Konda, Loura & 2 & 4 & 2 & 4 & Male & 27 and 40 \\
\hline Waimangura, West Wewewa & 1 & 5 & 1 & 5 & Male & 46 \\
\hline Jakarta & 0 & 8 & 0 & 8 & - & - \\
\hline Total & 4 & 28 & 4 & 28 & & \\
\hline
\end{tabular}

CATT=card agglutination test for trypanosomiasis; FELISA=field enzyme-linked immunosorbent assay 
evansi results. ${ }^{23}$ This indicates the presence of active infection of T. evansi in the area, where the parasite might attack both humans and livestock.

Shegokar et $\mathrm{al}^{24}$ mentioned that an epidemiologic surveillance study is required to follow up the seropositive findings of people living in a Surra outbreak area. They conducted whole blood analysis and demonstrated that 410 of 1,806 (22.7\%) people living in a human Surra outbreak area were seropositive to T. evansi. However, no parasites were detected in the blood of 60 persons who were positive at a high serum dilution ( $\geq 1: 4)$. The authors suggested investigation of trypanosomiasis in any human Surra outbreak region where T. evansi is endemic in livestock, such as in Indonesia. Another study also reported that 1 of 30 (3.3\%) workers raising camel in Egypt was positive on the basis of ELISA antibodies and blood smear analyses. Although some islands in Indonesia are known to be Surra endemic areas, there are no data reporting a serological study of the disease in humans who live and have contacts with livestock. Therefore, a serological survey of Surra in humans was conducted in Sumba Island when the outbreak occurred in 2010-2012.

The present study focused on farmers exposed to T. evansi who were in contact with livestock. Serological surveillance of anti-T. evansi antibodies was conducted in farmers living in three subdistricts of Southwest Sumba. The majority of the people living in the villages consists of traditional farmers and raise livestock. They have intensive contact with their livestock every day, which puts them at a high risk, particularly if the livestock is infected by infectious agents such as $T$. evansi. ${ }^{4}$

Previous studies have also used CATT/T. evansi and FELISA to detect antibodies in the serum or plasma of farmers. ${ }^{5,24}$ The CATT/T. evansi technique has been applied in several countries for serological surveys in humans and livestock, whereas the FELISA technique was developed at our laboratory based on ELISA applied to livestock only. The antigen coated on the FELISA immunostick was obtained from an Indonesian strain of T. evansi and can detect various strains of $T$. evansi in Indonesia. Meanwhile, the antigen used in CATT/T. evansi is commercially available. The latter method has been generally applied to detect seropositivity of T. evansi in humans (India, Egypt, and Vietnam). In terms of the results of the serological tests, there were no differences in responses between positive samples analyzed using either CATT/T. evansi or FELISA. However, based on sera dilution of the samples, the FELISA method was found to be more sensitive than CATT/T. evansi.

At least two hypotheses can be used to explain why the CATT/T. evansi result had less sensitivity compared to that of FELISA. First, the antigen coated on the CATT/T. evansi kit might not have been isolated from the Indonesian strain of T. evansi. Second, the parasite could have been lysed in the body or the parasite did not exist in the body for a long time. The second hypothesis was consistent with that reported of Joshi et al $^{5}$ who evaluated the level of specific antibodies in a patient at a high plasma dilution (1:64) when he was infected with high parasitemia (approximately $10^{6}$ trypanosomes $/ \mathrm{ml}$ ). After 24 hours or 3 months after being treated with suramin, the CATT/T. evansi result was positive at plasma dilutions of 1:16 and 1:4, respectively. The sensitivity of plasma gradually decreased after 6 months of treatment. Positivity was detected at only 1:2 sera dilution. These results indicated that the decrease in seropositivity was probably due to lysis of the parasite in the body. In the present study, the farmers' sera were collected in 2012 when the number of Surra cases in Sumba had declined due to intensive drug treatment, surveillance, and vector elimination. This might have contributed to the low level of seropositivity result.

In general, T. evansi cannot infect humans because of the presence of the trypanolytic factor APOL1, which eliminates the parasite from the body. ${ }^{11}$ The case of Surra that infected the farmer in India was due to the unavailability of APOL1 in his body. ${ }^{5}$ During that time, all scientists believed that a defect in APOL1 was the primary factor responsible for atypical human trypanosomiasis infection. ${ }^{4}$ However, this theory became controversial after a case of Surra infection reported in an individual in Vietnam..$^{10}$ In that case, the Vietnamese lady had normal serum with APOL1 and did not suffer from immunosuppression, but she was infected with T. evansi and exhibited long intermittent fever as a clinical symptom. Unfortunately, this study was not followed by APOL1 analysis, due to which we are not aware whether the farmers who were seropositive were deficient in APOL1. Surra infections in farmers have been reported to be caused due to their frequent contact with vectors of Surra. Ekawasti et $\mathrm{al}^{25}$ reported the presence of a highly abundant population of hematophagous flies in Sumba, which increased the 
probability of transmission of T. evansi to the farmers.

As far as the authors knowledge, the present study using serological tests in humans living in Sumba Island is the first report of seropositivity to T. evansi in Indonesia. This finding is extremely important to demonstrate that Surra might be a new potentially emerging disease that exposes people in an endemic area to a high risk of infection. In addition, this finding has implication as an early warning to people who have contact with livestock. It is highly recommended to pay attention when seropositive Surra infection is found in humans, particularly in an endemic area.

According to Brun, ${ }^{26}$ there are at least two scenarios through which humans can be infected with T. evansi. First, the parasite is mutated to a form that can resist the lytic factor in the human plasma. Due to mutation, the parasite could escape from the trypanolytic activity. Lai et al' ${ }^{13}$ reported that $T$. evansi stock isolated from China could survive in NHS. The isolate was found to be resistant after being challenged with NHS and inoculated into mice for 25 times. In the $20^{\text {th }}$ passage, the T. evansi stock isolated from China became resistant to NHS, including the serum containing APOL1 (the trypanolytic factor). Lai et $\mathrm{al}^{13}$ also demonstrated that T. evansi stocks isolated from different geographic regions developed a high level of natural resistance to NHS. They examined 15 isolates of T. evansi from different stocks, i.e., China, Vietnam, Kazakhstan, and the Philippines, against NHS both in vitro and in vivo and found that 5 of 15 isolates were resistant to NHS.

Second, the human host could be deficient in the lytic factor (APOL1) in the plasma. Vanhollebeke et al ${ }^{6}$ demonstrated that $T$. evansi infection was caused due to frameshift mutations in both APOL1 alleles in their study patient. Two mutations within the gene encoding APOL1, in codons 142 and 266, were identified and associated with $T$. evansi susceptibility in the patient. This generated an unexpected termination of protein translation by internal stop codons, which resulted in the total absence of APOL1. The defective APOL1 in the serum of the person with $T$. evansi infection did not demonstrate lytic activity against T. evansi. ${ }^{2}$

According to Desquesnes et $\mathrm{al}^{4}{ }^{4}$ the abnormalities found in the production mechanism of APOL1 are not the only factor that lead to the development of $T$. evansi infection in humans, but people suffering from immunosuppression are also at high risk of developing T. evansi infection, particularly among those living in regions where the parasite is endemic. Wabale et $\mathrm{al}^{27}$ reported a case of trypanosomiasis caused by $T$. evansi in a patient infected with retrovirus and lymphadenitis from Mumbai, India. The patient was immunocompromised, which may have facilitated the infection of T. evansi.

A recent case of human trypanosomiasis caused by T. evansi infection was reported from Vietnam. ${ }^{10}$ The parasite infected a 38-year-old woman breastfeeding a healthy infant. Parasitological, serological, and PCR analyses confirmed that the woman had Surra infection. Interestingly, the woman was a healthy person who had not previously described immunological risk factors for Trypanosoma infection and did not have the genetic mutations associated with APOL1 deficiency and serum concentrations. She became infected with the parasite through a wound while butchering raw beef. This indicates that a normal person is also at a high risk of being infected with $T$. evansi.

Although the present study had successfully demonstrated seropositivity to T. evansi in farmers, there are still certain limitations. Because the farmers' sera were obtained from sera bank, there were no data about the clinical symptoms. Moreover, the presence of T. evansi in the farmers could not be confirmed by molecular analysis such as PCR, even for parasitological examination, because of the unavailability of blood samples. The study was also not followed by APOL1 analysis.

In conclusion, farmers who have intensive contact with livestock in Surra outbreak areas can potentially develop antibodies to T. evansi. This indicates that there is frequent contact between the positive vectors such as hematophagous flies carrying T. evansi and the farmers. Additional large-scale studies are warranted to assess the zoonotic potential of this disease by conducting joint research with relevant public health authorities and the Agricultural Ministry on T. evansi infection (Surra).

\section{Conflict of Interest}

The authors affirm no conflict of interest in this study.

\section{Acknowledgment}

The authors thank drh. Suhardono MVSc Ph.D and drh. Didik Tulus Subekti, MKes (Department of Parasitology, Research Centre for Veterinary Science); drh. Vivi Veronica (Local Livestock services district of Southwest Sumba), Mr. Daud (Public Health Centre, Walandimu, Southwest Sumba), Dr. Hendra Wijaya and Health Office District of Southwest Sumba for the technical assistance and material support.

Funding Sources

None. 


\section{REFERENCES}

1. Truc P, Büscher P, Cuny G, Gonzatti MI, Jannin J, Joshi P, et al. Atypical human infections by animal trypanosomes. PLoS Negl Trop Dis. 2013;7(9):e2256.

2. Powar RM, Shegokar VR, Joshi PP, Dani VS, Tankhiwale NS, Truc $P$, et al. A Rare case of human trypanosomiasis caused by Trypanosoma evansi. Indian J Med Microbiol. 2006;24(1):72-4.

3. Gutierrez C, Desquesnes M, Touratier L, Büscher P. Trypanosoma evansi: recent outbreaks in Europe. Vet Parasitol. 2010;174(12):26-9.

4. Desquesnes $M$, Dargantes A, Lai DH, Lun ZR, Holzmuller P, Jittapalapong S. Trypanosoma evansi and surra: a review and perspectives on transmission, epidemiology and control, impact, and zoonotic aspects. Biomed Res Int. 2013;2013:321237.

5. Joshi PP, Shegokar VR, Powar RM, Herder S, Katti R, Salkar HR, et al. Human trypanosomiasis caused by Trypanosoma evansi in India: the first case report. Am J Trop Med Hyg. 2005;73(3):491-5.

6. Vanhollebeke B, Truc P, Poelvoorde P, Pays A, Joshi PP, Katti $R$, et al. Human Trypanosoma evansi Infection linked to a lack of apolipoprotein L-I. N Engl J Med. 2006;355(26):2752-6.

7. Da Silva AS, Duck MR, Fanfa Vda R, Otto MA, Nunes JT, Tonin AA, et al. Trypanocidal activity of human plasma on Trypanosoma evansi in mice. Rev Bras Parasitol Vet. 2012;21(1):55-9.

8. Pérez-Morga $D$, Vanhollebeke $B$, Paturiaux-Hanocq $F$, Nolan DP, Lins L, Homblé F, et al. Apolipoprotein L-I promotes trypanosome lysis by forming pores in lysosomal membranes. Science. 2005;309(5733):469-72.

9. Lun ZR, Reid SA, Lai DH, Li FJ. Atypical human trypanosomiasis: a neglected disease or just an unlucky accident? Trends Parasitol. 2009;25(3):107-8.

10. Lai DH, Wang QP, Li Z, Luckins AG, Reid SA, Lun ZR. Investigations into human serum sensitivity expressed by stocks of Trypanosoma brucei evansi. Int J Parasitol. 2010;40(6):705-10.

11. Van Vinh Chau N, Buu Chau L, Desquesnes M, Herder S, Phu Huong Lan N, Campbell Jl, et al. A clinical and epidemiological investigation of the first reported human infection with the zoonotic parasite Trypanosoma evansi in Southeast Asia. Clin Infect Dis. 2016;62(8):1002-8.

12. Gutierrez C, Juste MC, Corbera J, Magnus E, Verloo D, Montoya JA. Camel trypanosomosis in the Canary Islands: assessment of seroprevalence and infection rates using the card agglutination test (CATT/T. evansi) and parasite detection tests. Vet Parasitol. 2000;90(1-2):155-9.

13. Singla L Das, Sharma A, Kaur P, Tuli A, Bhat SA, Bal S, et al.
Bovine trypanosomosis in Punjab: assesment of seroprevalence by CATT/T. evansi. Int J Adv Res. 2013;1(9):364-71.

14. Bajyana Songa E, Hamers R. A card agglutination test (CATT) for veterinary use based on an early VAT RoTat $1 / 2$ of Trypanosoma evansi. Ann Soc Belg Med Trop. 1988;68(3):233-40.

15. Elhaig MM, Youssef Al, El-Gayar AK. Molecular and parasitological detection of Trypanosoma evansi in camels in Ismailia, Egypt. Vet Parasitol. 2013;198(1-2):214-8.

16. Mastra IK. Seroprevalensi trypanosomiasis di Pulau Sumbawa, Propinsi Nusa Tenggara Barat. Bul Vet. 2011;XXIII(79):131-8.

17. Ngaira J, Bett B, Karanja SM, Njagi EN. Evaluation of antigen and antibody rapid detection test for Trypanosoma evansi infection in camels in Kenya. Vet Parasitol. 2003;114(2):131-41.

18. Subekti D, Kusumaningtyas E. ELISA dan aglutinasi lateks. J IImu Ternak dan Vet. 2011;224-33.

19. Ditjenak. Pedoman pengendalian dan pemberantasan penyakit Trypanosomiasis (Surra). Direktorat Kesehatan Hewan, Direktorat Jenderal Peternakan dan Kesehatan Hewan Kementrian Pertanian. 2012.

20. Verloo D, Holland W, My LN, Thanh NG, Tam PT, Goddeeris B, et al. Comparison of serological tests for Trypanosoma evansi natural infections in water buffaloes from north Vietnam. Vet Parasitol [Internet]. 2000;92(2):87-96. Available from: http:// linkinghub.elsevier.com/retrieve/pii/S0304401700002843

21. Wardhana AH, Suhardono, Sawitri D, Subekti D. Karakterisasi molekuler dan derajat patogenitas Trypanosoma evansi isolat lokal Indonesia pada sapi dan kerbau. Laporan Penelitian APBN Balai Besar Penelitian Veteriner Bogor; 2012.

22. Shegokar VR, Powar RM, Joshi PP, Bhargava A, Dani VS, Katti $\mathrm{R}$, et al. Short report: human trypanosomiasis caused by Trypanosoma evansi in India: preliminary serologic survey of the local population. Am J Trop Med Hyg. 2006;75(5):869-70.

23. Ekawasti F, Sawitri D, Wardhana A. Perbandingan Metode Penyimpanan Darah Vektor Surra (Lalat Haematophagus) Untuk Analisis Multiplex Polimerase Chain Reaction. Seminar Nasional Peternakan dan Veteriner. 2014. p. 209-17.

24. Brun R. Human Asian trypanosomiasis, a new threat to human health? Am J Trop Med Hyg. 2005;73(3):484.

25. Wabale V, Nalage P, Joshi A, Bharadwaj R, Desphande K, Chowdhary A. Human Asian trypanosomiasis due to Trypanosoma evansi: a rare case. J Adv Parasitol. 2015;2(3):65-8.

26. Das S. Trypanosomiasis-India (WestBengal) [Internet].[Cited July 2017]. Available from: http://www.promedmail.org/direct. php? id=20050120.0197.

27. Haridy FM, El-Metwally MT, Khalil HH, Morsy TA. Trypanosoma evansi in dromedary camel: with a case report of zoonosis in greater Cairo, Egypt. J Egypt Soc Parasitol. 2011;41(1):65-76. 